\title{
MARKETING E INOVAÇÃO: O IMPACTO DA GESTÃO DE DESENVOLVIMENTO DE NOVOS PRODUTOS NO SUCESSO DAS INOVAÇÕES NA SIDERURGIA BRASILEIRA
}

Leonardo de Oliveira Turani ${ }^{1}$ Ed Juarez Mendes Tais ${ }^{2}$

\section{Resumo}

A siderurgia brasileira tem empreendido imensos esforços para se posicionar junto ao mercado consumidor como fornecedora de soluções, inovando na oferta de aços mais leves e resistentes, por meio do desenvolvimento contínuo de seus produtos. Diante desse contexto, esse artigo buscou investigar a gestão de projetos de novos produtos na siderurgia brasileira de aços planos, por meio de um estudo de caso do Sistema Usiminas, identificando como as atividades de marketing se desenrolam ao longo do processo de desenvolvimento e o impacto que têm no sucesso ou fracasso dos novos produtos. Por meio de entrevistas semi-estruturadas e em profundidade, além de pesquisa documental, foi possível identificar como a gestão moderna de desenvolvimento de novos produtos implementada por essa organização tem viabilizado inovações em curto espaço de tempo no mercado siderúrgico. Para isso, o marketing exerce um papel fundamental na gestão estratégica do desenvolvimento de produtos, por meio do planejamento estratégico e do acompanhamento de lançamento de novos produtos, além de ser co-responsável pelas séries de atividades do processo gerencial de inovações da organização.

Palavras-chave: Desenvolvimento de produtos; Marketing; Inovação.

\section{MARKETING AND INNOVATION: THE INFLUENCE OF DEVELOPMENT NEW PRODUCT MANAGEMENT IN THE SUCCESS OF INNOVATIONS INTO METALLURGICAL SECTOR}

\begin{abstract}
s
The Brazilian Steelmakers has been undertaking extensive efforts to position the marketplace close to as supplier of solutions, innovating in the offer to lighter projects, through the continuous development of his products. Inside of this context, this article looked for to investigate the management of new products projects in the Brazilian metallurgy of plane steels, through a study of case of the Sistema Usiminas, identifying as the marketing activities is covered along the development process and the impact that have in the success or failure of the new products. Through semi-structured interviews and in depth, besides documental research, it's identified as the modern development new products management implemented by this organization it has been making possible innovations in short space of time in the metallurgical market. For that, marketing gets a fundamental paper in the business and development new product strategies, besides being co-responsible for the series of activities of the managerial process of innovations of the organization.
\end{abstract}

Key words: Development products; Marketing; Innovation.

\section{INTRODUÇÃO}

No atual ambiente de mercado competitivo e dinâmico, muitas empresas entendem que o desenvolvimento contínuo e a introdução de novos produtos são a chave para o crescimento e a perenidade das organizações. Neste sentido, a Siderurgia Mundial tem empreendido imensos esforços para se posicionar junto ao mercado consumidor como fornecedora de soluções, inovando na oferta de aços mais resistentes, que proporcionam redução de peso e alta conformabilidade, fazendo frente a produtos sucedâneos que ameaçam posição de destaque do aço no mercado de bens industriais. ${ }^{(1)}$

\footnotetext{
' Engenheiro Metalurgista; Mestrando em Administração pela UFMG; MBA em marketing pela UFMG e Comércio Exterior pela FGV; Analista de marketing do Sistema Usiminas; Superintendencia de marketing - Sistema Usiminas, Rua Professor José Vieira de Mendonça, 301 I - Engenho Nogueira - 31310-260 - Belo Horizonte - MG.

${ }^{2}$ Engenheiro Metalurgista; Especialista em Finanças pela FDC e MBA em Comércio Exterior pela FGV; Coordenador de marketing do Sistema Usiminas; ; Superintendencia de marketing - Sistema Usiminas, Rua Professor José Vieira de Mendonça, 30II - Engenho Nogueira - 31310-260 - Belo Horizonte - MG.
} 
As inovações observadas no mercado siderúrgico mundial vão desde uma simples variação do produto existente ao totalmente novo, ou seja, uma inovação de fato. Kotler ${ }^{(2)}$ utiliza categorias de novos produtos, em termos de novidades para a empresa e para o mercado, indo de um produto totalmente novo a acréscimos e/ou melhorias em linhas já existentes, produtos antigos para a empresa lançados em novos mercados e ainda novos produtos com desempenho semelhante a custo mais baixo.

$\mathrm{Na}$ tentativa de minimizar os riscos e incertezas, inerentes ao processo de desenvolvimento de novos produtos (DNP), as empresas buscam informações não só junto aos clientes, mas também dentro da própria empresa. ${ }^{(2)}$ Para que se consiga monitorar e entender o mercado atual, há que se administrar o fluxo de dados existentes de tal forma a utilizá-los em informações capazes de proporcionar o entendimento da evolução nas mudanças das necessidades e anseios dos clientes, da possibilidade de fornecimento à novos segmentos, das iniciativas e novidades da concorrência, assim como das alterações nas matérias-primas e nos canais de distribuição.

Um fator determinante para garantia do sucesso e da manutenção de clientes lucrativos está na capacidade das áreas de marketing identificarem boas idéias, seja para aprimoramento de um produto já existente, seja para o desenvolvimento de um produto ou um mercado totalmente novo. Todo processo de desenvolvimento de novos produtos requer informações precisas, investimento em recursos humanos, criatividade, talento, recursos financeiros e um considerável esforço da empresa, além do tempo investido, que pode ser perdido caso o processo não se concretize com o êxito esperado.

Deschamps e $\mathrm{Nayak}^{(3)}$ conceituam o processo de DNP como um "caos bem organizado que, a partir de múltiplas interações, resulta na criação de um produto, cujo princípio é atender às necessidades dos clientes e garantir a sobrevivência e o crescimento da organização". Diversas são as formas de prover um aumento da probabilidade de sucesso e a eficácia na criação e desenvolvimento de novos produtos, tais como: o provimento de informações analíticas adequadas e confiáveis aos responsáveis pelo desenvolvimento; um planejamento adequado às realidades do mercado e às capacidades operacionais; bem como o comprometimento da alta administração com as estratégias de novos produtos.

As atividades relacionadas ao desenvolvimento de novos produtos demandam competências de indivíduos de várias áreas das empresas sendo que o sucesso da equipe depende do resultado de cada um. Robert ${ }^{(4)}$ sugere que o processo de geração de novos produtos deva envolver todos os membros da cadeia de geração do novo produto, de consumidores aos fornecedores.

A concepção tradicional do processo de desenvolvimento de produtos é fundamentada pela especialização funcional, legado da abordagem mecanicista de Taylor, Ford e Fayol, que utiliza a especialização como meio de obter eficiência nos processos organizacionais. De acordo com Kruglianskas, ${ }^{(5)}$ essa perspectiva já não consegue atender, em tempo hábil, aos novos prazos de desenvolvimento estabelecidos pelo mercado, em função do excessivo trabalho individual, procedimento esse que dificulta a comunicação, além de restringir o conhecimento tecnológico do produto de maneira segmentada e dispersa; do baixo envolvimento dos clientes e fornecedores; e dos equívocos que ocorrem na comunicação, devido à ambigüidade.

Em complemento, $\operatorname{Trott}^{(6)}$ delineia uma concepção moderna do processo de desenvolvimento de produtos com foco no resultado, cuja orientação está intimamente relacionada à participação dos clientes no processo, uso de estrutura multifuncional e matricial, e maior comprometimento dos participantes em todas as etapas do processo.

Dentro desse contexto, é relevante afirmar que o desenvolvimento de produtos passa por transformações que provocam sua evolução. Essa evolução é necessária para a sobrevivência da organização, em que a força motriz é o cliente. Os dirigentes das organizações socializam a importância de reconhecer o potencial do processo de desenvolvimento de produtos e a monitoração de suas tendências, pois assim poderão estabelecer estratégias com maior probabilidade de sucesso.

Em virtude das mudanças paradigmáticas, que passam os processos de desenvolvimentos de novos produtos dentro das organizações, da importância da área mercadológica nesse processo tanto no nível estratégico quanto operacional, como condição de sucesso ou fracasso de uma inovação, além da relevância do setor siderúrgico dentro da economia mundial, abordar a perspectiva dos fatores condicionantes das inovações e o papel do marketing industrial na Gestão de Desenvolvimento de Novos Produtos se mostra relevante, sendo o propósito dessa pesquisa ao realizar um estudo de caso nas duas usinas siderúrgicas do maior complexo siderúrgico de aços planos da América Latina: O Sistema Usiminas.

\section{MÉTODOS}

O caráter qualitativo e exploratório dessa pesquisa se deve à necessidade de obter uma melhor compreensão de variáveis relevantes no âmbito das pesquisas sobre desenvolvimento de produtos e inovação. ${ }^{(7)}$ Mattar $^{(8)}$ defende que a pesquisa exploratória deva ser utilizada na busca de explicações alternativas e complementares, mesmo em situações onde o assunto já tenha sido pesquisado.

Portanto, o objetivo desse estudo exploratórioé de buscar maior familiaridade com fenômeno inovação e novos produtos no contexto industrial brasileiro, a fim de melhor compreendê-lo por meio de descobertas de idéias e conhecimentos em situações onde haja lacunas empíricas.

Nessa investigação empírica de natureza exploratória utilizou-se o método do Estudo de 
casos, devido ao caráter de detalhamento e profundidade, eà complexidade do assunto e da necessidade de observação de evidências no contexto base. ${ }^{(9)}$ Esta metodologia se mostra adequada ao objetivo da pesquisa devido à necessidade de compreensão e explicação dos processos de desenvolvimento de novos produtos no contexto brasileiro, especificamente no siderúrgico. Além disso, tal metodologia propicia novas perspectivas em tópicos já pesquisados em contextos diferentes, de forma a fornecer mais critérios para auxiliar na compreensão das constatações de pesquisas descritivas. ${ }^{(7)}$

Foram utilizadas as técnicas de pesquisa documental com o intuito de obter dados secundários, e de campo por meio de entrevistas semi-estruturadas e não declaradas, baseadas em um roteiro pré-estabelecido percorrido com os analistas e especialistas das áreas de Atendimento à Clientes e de Desenvolvimento de Produtos da Usiminas e Cosipa com o objetivo de coletar dados básicos ao desenvolvimento do pesquisa.

\section{ANÁLISE DOS DADOS}

\section{I O Sistema Usiminas}

Considerado como maior complexo siderúrgico de aços planos da América Latina, o Sistema Usiminas é líder no fornecimento de aços planos no mercado brasileiro, que de acordo com o IBS - Instituto Brasileiro de Siderurgia, detém $52 \%$ de participação no mercado, por intermédio de suas duas usinas siderúrgicas: a Usiminas - Usinas Siderúrgicas de Minas Gerais, com sua unidade produtiva em Ipatinga (MG); e a Cosipa - Companhia Siderúrgica Paulista, com sua unidade produtiva em Cubatão (SP).

A Usiminas e a Cosipa possuem uma gestão de desenvolvimento de novos produtos integrada desde 2005. Ambas são responsáveis pela produção e comercialização de todo o portfólio de produtos em aços planos do Sistema Usiminas: Placas, Chapas Grossas, Laminados a Quente, Laminados a Frio, Galvanizados por imersão a quente, Eletrogalvanizados, além de Produtos Beneficiados, que suprem os mais diversos segmentos industriais.

Com essa carteira de produtos, o Sistema Usiminas atende plenamente os segmentos de mercados como: Indústria Automotiva, Vasos de Pressão, Tubos, Indústria Naval, Construção Civil, Eletrodomésticos, Máquinas Agrícolas e Elétro-eletrônica, entre outros. De acordo com seu balanço comercial, no ano de 2006, a Usiminas e Cosipa obtiveram juntas um faturamento líquido da ordem de $\mathrm{R} \$ 12$ bilhões, comercializando no mercado nacional mais de 5,3 milhões de toneladas de produtos, o que representa cerca de $67 \%$ do total se suas vendas.

\subsection{O Processo de Desenvolvimento de Novos Produtos na Usiminas e Cosipa}

O processo de desenvolvimento de novos produtos (DNP) na Usiminas e Cosipa caracteriza-se pela variedade de funções e departamentos funcionais envolvidos ao longo do processo, com uma série de atividades interligadas, cujas as principais características são identificadas no Quadro I.
Quadro I. Características do processo de DNP do Sistema Usiminas.

\begin{tabular}{|c|c|}
\hline Características & Descrição \\
\hline $\begin{array}{l}\text { Estrutura } \\
\text { organizacional }\end{array}$ & $\begin{array}{l}\text { Estrutura por processos. Coordena- } \\
\text { ção geral de responsabilidade do mar- } \\
\text { keting, sendo cada projeto de novo } \\
\text { produto dividido por equipes de pro- } \\
\text { jetos de produtos. }\end{array}$ \\
\hline $\begin{array}{l}\text { Equipes de } \\
\text { projetos }\end{array}$ & $\begin{array}{l}\text { Matricial, com participação integral do } \\
\text { marketing (líder), P\&D e Metalurgia, } \\
\text { e participação parcial das áreas de } \\
\text { produção, vendas, logística e PCP. Os } \\
\text { integrantes participam do processo } \\
\text { desde a geração de idéias até a com- } \\
\text { ercialização final do novo produto. }\end{array}$ \\
\hline $\begin{array}{l}\text { Fases do } \\
\text { processo de } \\
\text { desenvolvimento }\end{array}$ & $\begin{array}{l}\text { Basicamente composto por } 8 \text { etapas, } \\
\text { sendo as } 3 \text { primeiras consideradas o } \\
\text { planejamento do desenvolvimento e } \\
\text { as demais como o desenvolvimento } \\
\text { do novo produto em si. }\end{array}$ \\
\hline Coms & $\begin{array}{l}\text { Reuniões periódicas entre as equipes } \\
\text { de projetos e da coordenação geral. } \\
\text { Relatórios executivos que contém o } \\
\text { status dos projetos em andamento } \\
\text { para toda área comercial e de quali- } \\
\text { dade. }\end{array}$ \\
\hline Gerais & $\begin{array}{l}\text { Participação do cliente no planeja- } \\
\text { mento inicial de desenvolvimento e } \\
\text { nos testes em campo. }\end{array}$ \\
\hline
\end{tabular}

Realizada basicamente por oito fases que se complementam, conforme indica a Figura I, o processo de DNP do Sistema Usiminas tem como característica diferencial as retro-alimentações de informações e tomadas de decisão ao longo do processo.

Uma descrição sucinta das principais etapas do processo de DNP do Sistema Usiminas é indicada no Quadro 2.

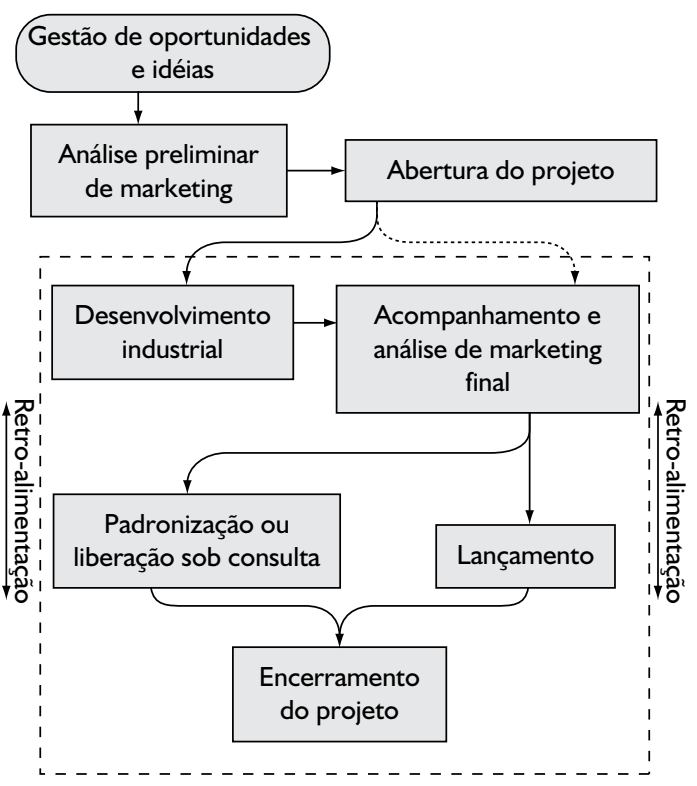

Figura I. Fluxo do processo de DNP do Sistema Usiminas. 
É importante ressaltar que, embora as equipes de P\&D não exercem coordenação em momento algum do processo, sendo apenas colaboradores do marketing e da Metalurgia, o setor de $P \& D$ é responsável pela execução de todos os desenvolvimentos em escala laboratorial, cujos projetos podem se inserirem na carteira de novos produtos ou não.

A utilização de uma estrutura organizacional matricial focada no desenvolvimento de novos produtos, envolvendo principalmente os setores de Pesquisa \& Desenvolvimento, marketing e Controle Metalúrgico, tem possibilitado ao Sistema Usiminas o destaque no desenvolvimento de aços de alta resistência e de performance superior no mercado siderúrgico brasileiro.
A estrutura organizacional estipulada para o processo de DNP no Sistema Usiminas foi arquitetada em função da natureza da indústria e do tipo de produto a ser desenvolvido. Conforme se verifica, a gestão de todo o processo é de competência de um coordenador geral de marketing, que delega a execução de cada projeto à um líder de equipe, que em conjunto com representantes de várias áreas funcionais da empresa executam o desenvolvimento do novo produto. Um exemplo dessa estrutura matricial de DNP é ilustrada pela Figura 2.

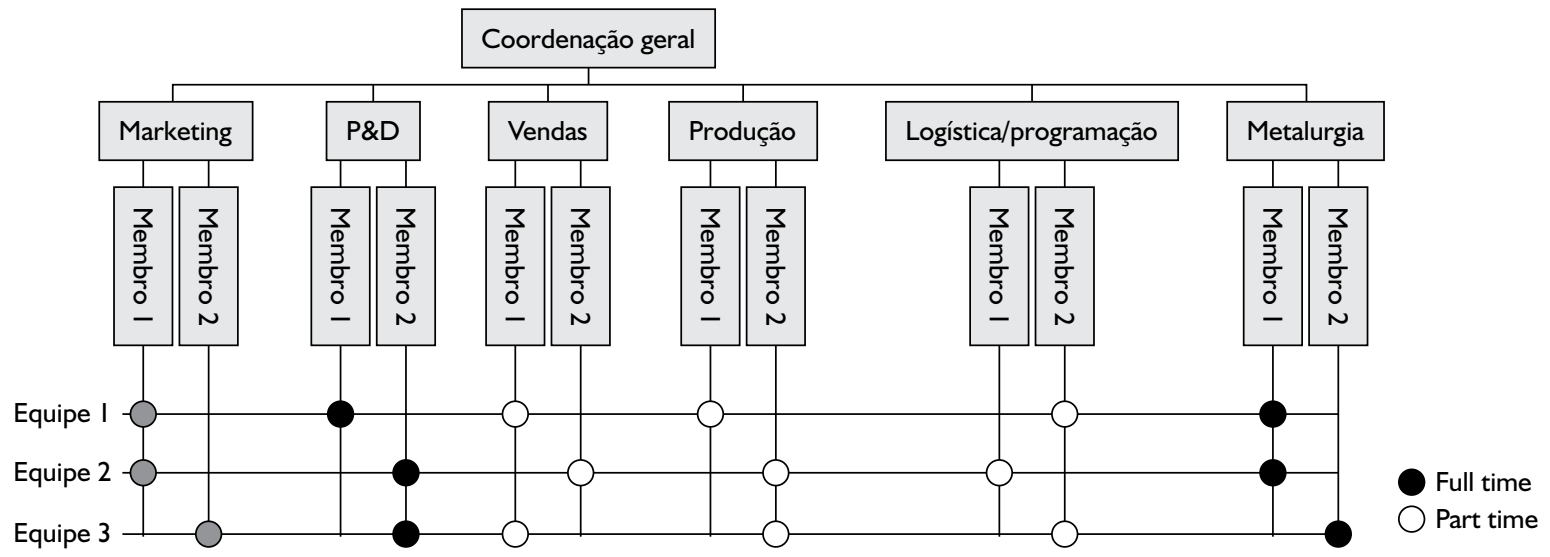

Figura 2. Estrutura matricial de DNP do Sistema Usiminas.

Quadro 2. Principais etapas do processo de DNP do Sistema Usiminas.

\begin{tabular}{|c|c|c|}
\hline Etapas & Descrição & Coordenação \\
\hline $\begin{array}{l}\text { Gestão carteira de } \\
\text { projetos }\end{array}$ & $\begin{array}{l}\text { Construção da base de conhecimento e da identificação de oportunidades de negócios obtidas pe- } \\
\text { los produtos existentes, acompanhamento das tendências tecnológicas, assistência técnica, Equipe } \\
\text { de vendas, Clientes, Concorrência e Sucedâneos. }\end{array}$ & Marketing \\
\hline $\begin{array}{l}\text { Análise preliminar de } \\
\text { marketing }\end{array}$ & $\begin{array}{l}\text { Indicam as características gerais do protótipo, expectativas de preços e custos, análise dos riscos e } \\
\text { do mercado, potencial de demanda, aspectos estratégicos e tendência tecnológicas. Os aspectos } \\
\text { técnicos são amplamente discutidos com os clientes parceiros para definições das variáveis funcio- } \\
\text { nais do novo produto e de sua aplicação. }\end{array}$ & Marketing \\
\hline Abertura do projeto & $\begin{array}{l}\text { Reunião oficial de abertura do projeto baseada nas indicações por definições estratégicas e de } \\
\text { viabilidade pela Análise preliminar de marketing, em que se definem a equipe de projetos, crono- } \\
\text { grama, objetivos, requisitos específicos e restrições operacionais, necessidades de escala piloto } \\
\text { (P\&D). }\end{array}$ & Marketing \\
\hline $\begin{array}{l}\text { Desenvolvimento } \\
\text { industrial }\end{array}$ & $\begin{array}{l}\text { Coordenada pela Metalurgia com parceria da equipe de P\&D, são definidos os lotes pilotos, ex- } \\
\text { periência industrial e testes em clientes. Momento em que se desenvolve industrialmente os lotes } \\
\text { experimentais. }\end{array}$ & Metalurgia \\
\hline $\begin{array}{l}\text { Acompanhamento e } \\
\text { análise final de } \\
\text { marketing }\end{array}$ & $\begin{array}{l}\text { Acompanhamento do mercado, concorrentes e tendências tecnológicas, bem como reavaliação } \\
\text { de análise mercadológica para subsidiar o programa de lançamento e precificação final do novo } \\
\text { produto. }\end{array}$ & Marketing \\
\hline Padronização & $\begin{array}{l}\text { Após a precificação e definição da terminologia do novo produto ocorre a padronização da quali- } \\
\text { dade de aço ou liberação de vendas sob consulta. }\end{array}$ & Metalurgia \\
\hline Lançamento & $\begin{array}{l}\text { Lançamento interno e externo, treinamento da equipe de vendas e atualização do catálogo de } \\
\text { produtos. }\end{array}$ & Marketing \\
\hline Encerramento & $\begin{array}{l}\text { Após a finalização da etapa de lançamento formaliza-se o encerramento do projeto. A partir daí, } \\
\text { são avaliadas sua performance comercial e de qualidade pelas Diretoria Comercial e Industrial, } \\
\text { respectivamente. }\end{array}$ & Marketing \\
\hline Gestão de produtos & $\begin{array}{l}\text { Gestão da performance comercial das linhas de produtos indicando lucratividade e volumes de } \\
\text { vendas, com apoio da Metalurgia na gestão do ciclo de vida por meio da análise da perfomance } \\
\text { operacional de qualidades de aço. }\end{array}$ & Marketing \\
\hline
\end{tabular}


Diante dessa perspectiva, nos últimos três anos, o Sistema Usiminas lançou no mercado siderúrgico 13 novos produtos, principalmente para os mercados automotivo e line pipe, itens que representaram $R \$ 390$ milhões de faturamento líquido no período e com potencial de aumentar suas vendas em $30 \%$ à $40 \%$ nos próximos 5 anos.

\section{DISCUSSÕES}

A estrutura matricial adotada pelo Sistema Usiminas implica diretamente em algumas vantagens como: a melhoria do canal de comunicação, a maior difusão das informações, a melhoria da cooperação e dos relacionamentos inter-funcionais. Tais características contribuem em muito para a redução do tempo de desenvolvimento, como também para ajustes no processo em virtude dos efeitos do mercado, das ações de concorrência e de restrições operacionais.

\section{I O papel do marketing no DNP}

A gestão geral do desenvolvimento de novos produtos do Sistema Usiminas é de responsabilidade da Superintendência de marketing, desenvolvendo ações de planejamento estratégico, controle e monitoramento de todo o processo de DNP. O processo de DNP adotado pelo Sistema Usiminas têm possibilitado a:

- Redução dos custos e melhoria da qualidade dos produtos, em função de um bom planejamento inicial do projeto, e devido o envolvimento dos clientes no processo de desenvolvimento de produtos;

- Redução do prazo de desenvolvimento, devido às melhorias de comunicação, os melhores trade-offs em projeto, as reduções de revisões e o desenvolvimento do projeto de processos simultâneo ao do produto;

- Aumento da flexibilidade, em função de um ambiente integrado e entrosado;

- Aumento da confiabilidade, por meio da prevenção de possíveis falhas e adoção de medidas preventivas às mesmas, desde a etapa de elaboração do projeto; e

- Melhoria da Imagem, reconhecida pelo mercado como uma empresa fornecedora de soluções.

Além disso, são identificadas algumas contribuições indiretas advindas do modelo de DNP adotado como:
- Redução da curva de aprendizado, em função da maior exposição a muitas fontes de informações, à aquisição de conhecimentos amplos e habilidades diversificadas pelos integrantes das equipes de projetos; e

- Transformação da cultura organizacional, por meio de mudanças na forma de agir e pensar dos funcionários.

\section{CONCLUSÕES}

O modelo de gestão de desenvolvimento de novos produtos do Sistema Usiminas se assemelha às concepções modernas encontrados na literatura, ${ }^{(6)}$ em que há foco no resultado e no planejamento inicial bem definido e consistente. São características principais do processo de desenvolvimento de novos produtos nessa organização: Equipes matriciais e inter-funcionais; Participação efetiva do cliente do início ao fim do processo; Foco na engenharia de aplicação e Utilização de tecnologias de processos para o aprimoramento de novos produtos.

O marketing exerce função primordial nas séries de atividades do processo gerencial de inovações da organização, seja do planejamento estratégico ao gerenciamento do processo de novos produtos, com ênfase no acompanhamento dos produtos recém - lançados. Essas estratégias de novos produtos têm impactado positivamente na comercialização de aços de última geração para os diversos mercados do setor de aços planos.

Diante disso, despontam alguns tópicos para debates e novas frentes de pesquisa tais como a influência do tempo de desenvolvimento de produtos e os impactos na competitividade da siderurgia brasileira, além da interface marketing e Engenharia de Aplicação e seus efeitos determinantes para o sucesso ou fracasso de um novo produto. 


\section{REFERÊNCIAS}

I ANDRADE, S.L.; PEREIRA, J.F;; TAISS, E.J. ULSAB-AVC. O aço no automóvel do futuro: A estratégia da Usiminas. In: CONGRESSO ANUAL DA ABM, 55., 2000, Rio de Janeiro/RJ. Anais... São Paulo: ABM, 2000.

2 KOTLER, P. Administração de marketing: a edição do novo milênio. São Paulo: Prentice Hall, 2000.

3 DESCHAMPS, J.P.; NAYAK, P.R. Produtos Irresistíveis: como operacionalizar um fluxo perfeito de produtos do produtor ao consumidor. São Paulo: Makron Books, 1997.

4 ROBERT, M. Product innovation strategy. New York: Mc Graw Hill, 1995.

5 KRUGLIANSKAS, I. Engenharia simultânea: organização e implantação e empresas brasileiras. In.: SIMPÓSIO NACIONAL DE GESTÃO DA INOVAÇÃO TECNOLÓGICA, 17., 1992, São Paulo. Anais... São Paulo: Edusp, 1992. p. 47-52.

6 TROTT, P. Innovation management and new product development. 2.ed. London: Prentice Hall, 2002.

7 YIN, R.K. Estudo de caso: planejamento e métodos. 2.ed. Porto Alegre: Bookman, 2005.

8 MATTAR, F.N. Pesquisa de marketing. São Paulo: Atlas, 1993.

9 MALHOTRA, N.K. Pesquisa de marketing: uma orientação aplicada. 3.ed. Porto Alegre: Bookman, 200I.

Recebido em: 27/03/2007

Aceito em: $7 / 12 / 07$

Proveniente de: CONGRESSO ANUAL DA ABM, 6I., 2007, Rio de Janeiro. São Paulo: ABM, 2007. 